\title{
Comparison of gait properties during level walking and stair ascent and descent with varying loads
}

\author{
Tomohiro Demura $^{1^{*}}$, Shin-ich Demura ${ }^{1}$, Sohee Shin $^{2}$ \\ ${ }^{1}$ Graduate School of Natural Science \& Technology, Kanazawa University, Kanazawa, Ishikawa, Japan; \\ *Corresponding Author: tomodemu@ed.kanazawa-u.ac.jp; \\ ${ }^{2}$ Kanazawa University Center for Innovation Venture Business Laboratory Kanazawa, Ishikawa, Japan.
}

Received 1 September 2010; revised 9 September 2010; accepted 16 September 2010

\begin{abstract}
This study aimed to compare gait properties during level walking and during stair ascent and descent with varying loads. Fifteen healthy young men (mean age: $22.1 \pm 1.6$ years) walked while holding four different loads relative to each subject's body mass $(0,20,40$ and $60 \%$ of body mass: BM) on their backs. Stance time, swing time, and double support times were selected as gait parameters. All parameters showed a maximal value during stair ascent and a minimum value during level walking. Stance and double support times increased significantly with each load during level walking and during stair ascent and descent. In conclusion, stair ascent and descent creates more unstable movement than level walking regardless of the weight of the load. The effect of loads on gait increases with the weight of the load and becomes obvious once the load exceeds $60 \%$ of BM.
\end{abstract}

Keywords: Gait; Stair Ascent; Stair Descent; Load

\section{INTRODUCTION}

Climbing up and down stairs is an important activity in daily life and has been studied mainly from kinetic and kinematic standpoints. It was reported that angle and moment of knee flexion are larger during stair ascent than during level walking [1,2]. According to Andriacchi et al. [1], knee flexion moment was roughly three times larger during stair ascent and hip flexion moment was about one and a half times larger during stair descent than during level walking.

The movement of ascending and descending differs considerably from level walking from a mechanical standpoint and requires great exertion of leg strength $[3,4]$. Because the center of gravity move up and down. Furthermore, while ascending, we must raise one foot higher than each step. Hence, it is assumed that because a single support time is longer during stair ascent and descent than during level walking, a large burden is imposed on the support leg and posture instability is increased.

In daily life, it is very popular to walk with a shopping bag in one or both hands, which can be a heavy burden. Until now, the issue of walking with loads has been mainly studied from the standpoint of walking speed [5] or energy cost [6]. According to Ghori and Luckwill [7], leg muscle activity increases and the ongoing electromyographic activity prolongs during level walking with loads. In addition, by holding loads, the body's center of gravity is raised and walking becomes more unstable [8, 9]. As a result, to maintain gait stability, gait changes such as a decrease in swing time [7] or an increase of double support time [10] occur.

From the above, it is assumed that stair ascent and descent with loads produces larger gait changes than level walking and that more instability results. The purpose of this study was to compare gait properties during level walking and during stair ascent and descent with varying loads.

\section{MATERIALS AND METHODS}

\subsection{Subjects}

Fifteen healthy young men without extremity disorders participated in this study (age: $22.1+/-1.6$ years, height: $172.5+/-4.9 \mathrm{~cm}$, body mass: $67.6+/-5.0 \mathrm{~kg}$ ). Before the measurements were taken, the purpose and procedure of this study were explained in detail and informed consent was obtained from all subjects.

\subsection{Material}

Gait properties were measured by a gait analysis system (Walk Way MG-1000, Anima, Japan) in reference to a previous study [11]. The MG-1000 with plate sensors can determine time, dimensions and the distance of the 
foot or feet when the foot touches its surface and can measure grounding/non-grounding on the bearing surface as an on/off signal. Data were recorded into a personal computer at $100 \mathrm{~Hz}$.

The stairs used for the present experiment consisted of four steps (step width: $90 \mathrm{~cm}$, step height: $20 \mathrm{~cm}$, tread length: $29 \mathrm{~cm}$ ) and was within the Japanese building code [12] step height: under $23 \mathrm{~cm}$, tread length: over 15 $\mathrm{cm}$ ) (see Figure 1).

\subsection{Protocol for Measurement}

In this study, we imposed varying weight loads on the subjects in reference to a previous study by Demura and Demura [11] (see Figure 2). In short, the subjects walked with four loads relative to each subject's body mass ( 0 , 20, 40 and $60 \%$ BM) on their backs. The trial order of each load condition was randomized. The movement during measurement was explained to the subjects before the measurements were taken. For stair ascent and descent, subjects went up the stairs (four steps), and walked straight about two meters on the stock, made a right about-face turn, and after standing still for a few seconds, went down the stairs (see Figure 1). To eliminate the influence of fatigue, the subjects performed each load condition twice with an enough rest. In addition, for stair ascent and descent, we used data of four steps from the first step foot on the stair for analysis.

During level walking, subjects were instructed to walk straight for eleven meters as normal. To eliminate a fatigue effect, the subjects walked under each load condition twice with a one minute rest. In addition, we used only the middle five meters of data excluding the first and final three meters for analysis.

\subsection{Parameters}

Figure 3 shows the gait property parameters selected in reference to a previous study Murray et al. [13]. A mean of two trials was used for analysis. Stance time equals the duration that the body is supported by one foot or both feet, that is, the phase in which one foot or both feet contact the floor. A swing time equals the duration that one foot is swinging, that is, one foot is off the floor. This corresponds with single-legged support time. Double support time equals the duration in which both feet are in contact with the floor.

\subsection{Data Analysis}

Mean differences among load and movement conditions for parameters were tested by repeated two-way analysis of variance (ANOVA: load condition $\times$ movement). When an interaction was significant, Bonferroni's method was selected for a multiple comparison. The statistical SPSS package ver. 11.0 (SPSS, America) was used for data analysis. The probability level of 0.05 was indicative of statistical significance.

\section{RESULTS}

Table 1 shows results of two-way ANOVA for gait parameters. A significant interaction is found in all parameters. In the results of multiple comparisons, stance time is significantly longer in the order of level walking, stair descent and ascent in all load conditions. In level walking, it is significantly longer in the order of $0 \%$ or 20\% BM, 40\% BM and 60\% BM. It was significantly longer in $60 \% \mathrm{BM}$ than $0 \%$ and $20 \% \mathrm{BM}$ in stair ascent and descent and in 60\% BM than $40 \% \mathrm{BM}$ in stair ascent.

Swing time is significantly longer in the order of level walking, stair descent and stair ascent at $0 \%$ and $20 \%$ $\mathrm{BM}$, in stair ascent than stair descent at 60\% BM, and in stair ascent and descent than level walking at $40 \%$ and $60 \%$ BM. In level walking, it is significantly longer at $40 \%$ or $60 \%$ BM than $0 \% \mathrm{BM}$ and at $40 \%$ BM than $20 \%$ BM.

The double support time in all load conditions was significantly longer in the order of level walking, stair

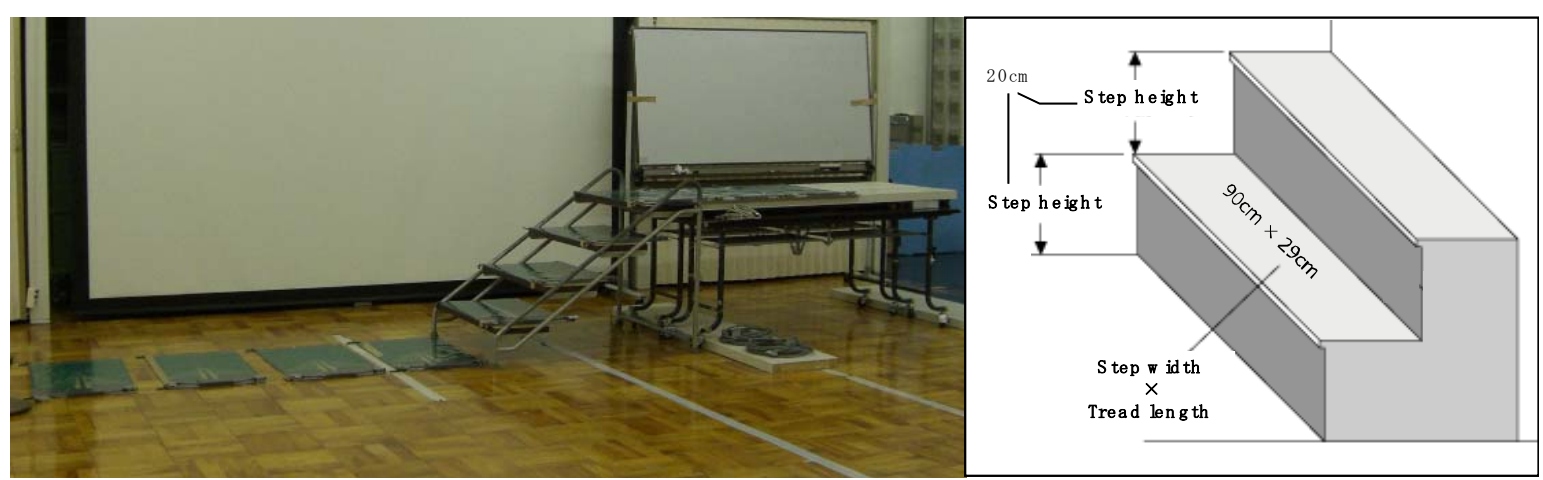

Figure 1. The stairs used for the present experiment consisted of four steps (step width: $90 \mathrm{~cm}$, step height: $20 \mathrm{~cm}$, tread length: 29 $\mathrm{cm})$. 
Table 1. Results of 2way-ANOVA during stair ascent and descent, and level walking with loads.

\begin{tabular}{|c|c|c|c|c|c|c|c|c|c|c|c|c|}
\hline & & \multicolumn{2}{|c|}{ 0\%BM } & \multicolumn{2}{|c|}{$20 \%$ BM } & \multicolumn{2}{|c|}{$40 \% \mathrm{BM}$} & \multicolumn{2}{|c|}{$60 \% \mathrm{BM}$} & \multicolumn{2}{|c|}{ ANOVA } & \multirow{2}{*}{$\begin{array}{c}\text { Post-hoc } \\
\text { Bonferroni }\end{array}$} \\
\hline & & Mean & SD & Mean & SD & Mean & SD & Mean & SD & factor & F-value & \\
\hline \multirow{3}{*}{$\begin{array}{c}\text { Stance } \\
\text { Time } \\
\text { (sec) }\end{array}$} & ascent & 0.78 & 0.07 & 0.82 & 0.07 & 0.89 & 0.11 & 0.96 & 0.12 & $\mathrm{~F} 1$ & 134.18 * & \multirow{3}{*}{$\begin{array}{l}\text { all loads: level < descent < ascent } \\
\text { ascent: } 0 \%<40 \%<60 \% \quad 20 \%<60 \% \\
\text { descent: } 0 \%<40,60 \% \quad 20 \%<60 \% \\
\text { level: } 0,20 \%<40 \%<60 \%\end{array}$} \\
\hline & descent & 0.70 & 0.05 & 0.74 & 0.06 & 0.80 & 0.10 & 0.85 & 0.13 & F2 & $18.25 *$ & \\
\hline & level & 0.63 & 0.03 & 0.64 & 0.04 & 0.66 & 0.04 & 0.68 & 0.05 & F3 & $5.52 *$ & \\
\hline \multirow{3}{*}{$\begin{array}{l}\text { Swing } \\
\text { Time } \\
\text { (sec) }\end{array}$} & ascent & 0.47 & 0.04 & 0.47 & 0.03 & 0.48 & 0.05 & 0.49 & 0.05 & $\mathrm{~F} 1$ & $55.61 *$ & \multirow{3}{*}{$\begin{array}{l}0,20 \% \text { : level }<\text { descent }<\text { ascent } \\
60 \% \text { : descent }<\text { ascent } \\
\text { 40,60\%: level < ascent, descent }\end{array}$} \\
\hline & descent & 0.44 & 0.04 & 0.43 & 0.04 & 0.46 & 0.06 & 0.47 & 0.06 & F2 & 1.17 & \\
\hline & level & 0.41 & 0.01 & 0.40 & 0.01 & 0.40 & 0.01 & 0.40 & 0.02 & F3 & $3.57 *$ & \\
\hline \multirow{3}{*}{$\begin{array}{c}\text { Double } \\
\text { Support } \\
\text { Time } \\
\text { (sec) }\end{array}$} & ascent & 0.15 & 0.02 & 0.17 & 0.02 & 0.20 & 0.04 & 0.24 & 0.05 & F1 & $68.12 *$ & \multirow{3}{*}{$\begin{array}{l}\text { all loads: level < descent < ascent } \\
\text { ascent: } 0 \%<20,40 \%<60 \% \\
\text { descent: } 0 \%<20,40,60 \% \quad 20 \%<60 \% \\
\text { level: } 0 \%<20 \%<40 \%<60 \%\end{array}$} \\
\hline & descent & 0.14 & 0.02 & 0.16 & 0.02 & 0.18 & 0.03 & 0.19 & 0.04 & F2 & $34.64 *$ & \\
\hline & level & 0.11 & 0.01 & 0.12 & 0.01 & 0.14 & 0.01 & 0.15 & 0.02 & F3 & $6.74 *$ & \\
\hline
\end{tabular}

F1: movement, F2: loads, F3: interaction, $*: \mathrm{p}<0.05$,

ascent: stair ascent, descent: stair descent, level: level walking

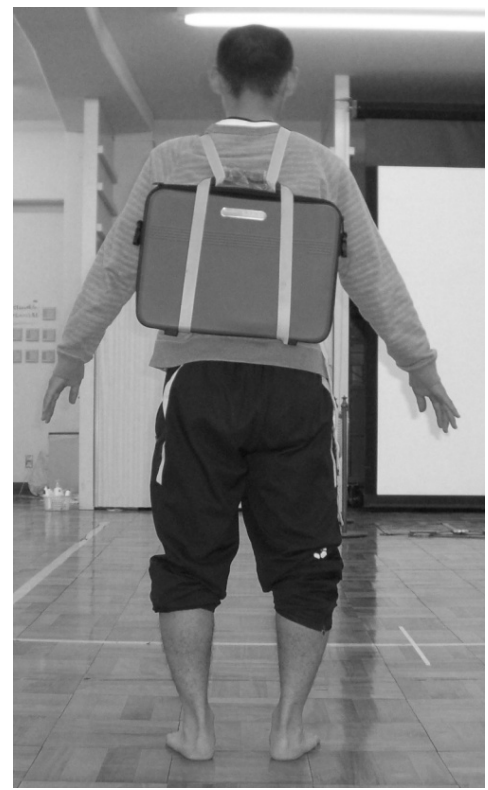

Figure 2. The varying weight loads on the subjects.

descent and ascent. In stair ascent, it is significantly longer in 60\% BM than 20\% and 40\% BM, and in 20\% and $40 \% \mathrm{BM}$ than $0 \% \mathrm{BM}$. In stair descent, it is longer in $20 \%, 40 \%$ and $60 \% \mathrm{BM}$ than $0 \% \mathrm{BM}$, and in $60 \%$ BM than 20\% BM.

\section{DISCUSSION}

\subsection{Effect of Loads}

Subjects walked the level plane and stairs with four loads relative to subject's body mass (0, 20, 40 and 60\% $\mathrm{BM})$. In level walking and stair ascent and descent, stance time and double support time increased with loads. It has been reported that energy consumption $[14,15]$ and the activity of erector spinae and gastrocnemial muscles increase [10,16] while walking with loads. Hence, walking with loads is considered to impose a large burden on the lower limbs.

Ghori and Luckwill [7] reported that the body's center of gravity is raised by holding heavy loads and that walking becomes unstable. Consequently, a decrease in swing time [7] and an increase in double support time [9, 10] occur to maintain a stable posture. In this study, the swing time was unchanged in spite of an increase in loads. However, the percentage of swing time to stride time decreased. This change is believed to be one of the strategies to keep a stable posture during walking.

\subsection{Comparison of Level Walking, and Stair Ascent and Descent}

Meanwhile, all parameters tended to be longer in the order of level walking, stair descent and ascent. When walking the same distance, stair ascent and descent have more phases which move the body's center of gravity more vertically than during level walking. Thus, it can be simply considered that gait time parameters became longer during stair ascent and descent than during level walking due to this extra vertical movement.

Ascending requires greater time and leg strength to raise the body on a step after the lifted leg has landed. It is assumed that because of this, ascending the stairs takes longer than descending them.

In addition, it was reported that an increase in double support time is to maintain stability of walking [17-20]. Also in this study, the double support time was longer during stair ascent and descent than during level walking. From the above, because the burden imposed on the body is larger during stair ascent and descent than during level walking, ascending and descending the stairs is considered to destabilize movement. 


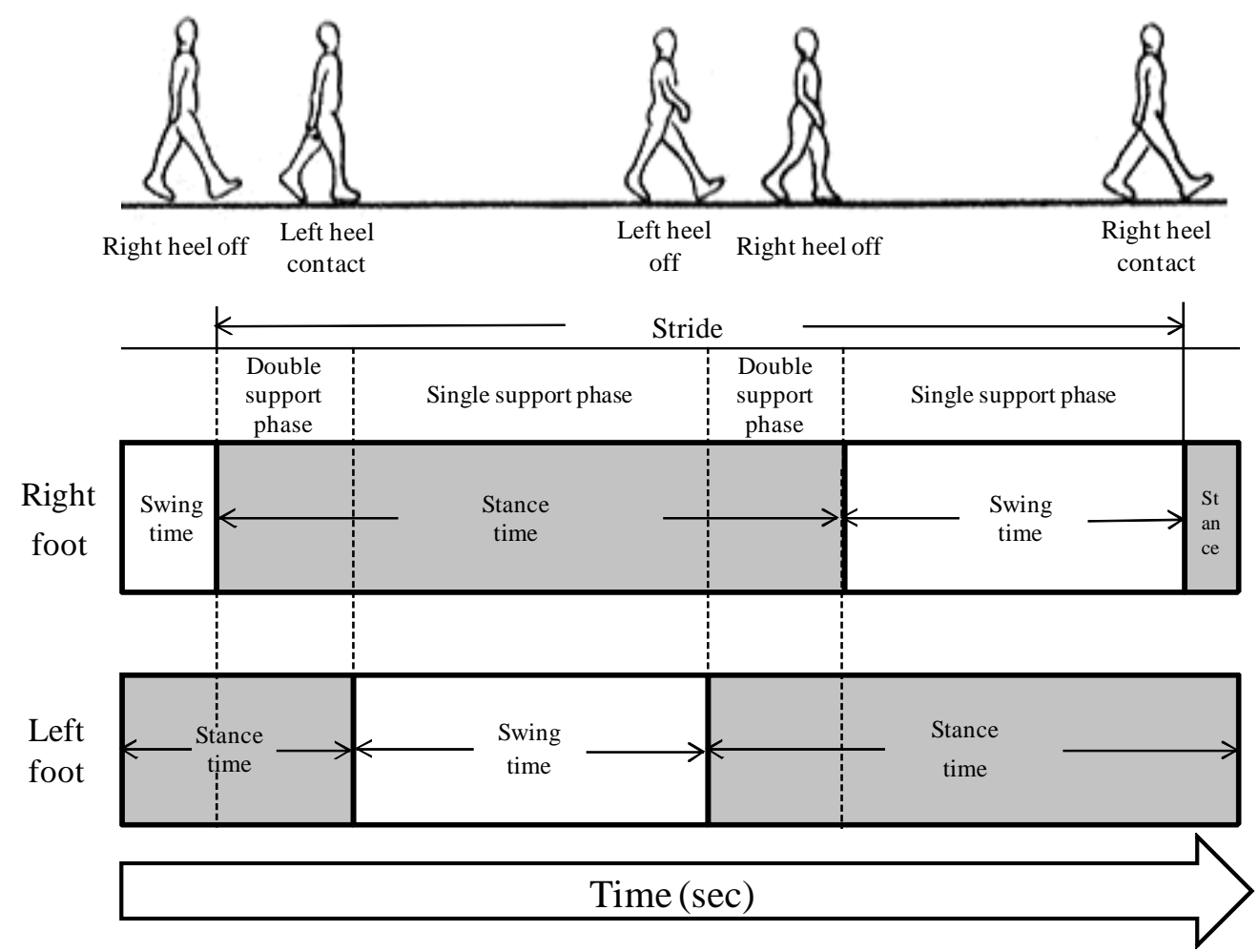

Figure 3. The gait property parameters regarding time.

Furthermore, gait parameters regarding time increased in all movements with loads. The effect of varying loads on stair ascent and descent was similar to that on level walking. In addition, the present results suggested that the effect of weight loads on gait properties increases with loads and becomes obvious at 60\% BM during level walking and during stair ascent and descent. This result agrees with that in the previous study $[7,21,22]$ that the change in gait became clear at over 50\% BM.

\section{CONCLUSIONS}

In conclusion, stance time, swing time and double support time are longer in the order of level walking, stair descent and ascent. In addition, stance time and double support time increased with loads during level walking and during stair ascent and descent. Ascending and descending the stairs is more unstable compared to level walking regardless of load weight. In addition, the effect of loads on gait becomes obvious in loads over $60 \%$ BM during level walking and while ascending and descending stairs.

\section{REFERENCES}

[1] Andriacchi, T.P., Andersson, G.B., Fermier, R.W., Stem, D. and Galante, J.O. (1980) A study of lower-limb mechanics during stair-climbing. The Journal of Bone \& Joint Surgery, 62, 749-757.
[2] Jevsevar, D.S., Riley, P.O., Hodge, W.A. and Krebs, D.E. (1993) Knee kinematics and kinetics during locomotor activities of daily living in subjects with knee arthroplasty and in healthy control subjects. Physical Therapy, 73, 229-238.

[3] Joeseph, J. and Watson, R. (1967) Telemetering electromyography of muscles used in walking up and down stairs. Journal of Bone Joint Surgery, 49-B, 774-780.

[4] James, B. and Parker, A.W. (1989) Electromyography of stair locomotion in elderly men and women. Electromyography and Clinical Neurophysiology, 29, 161-168.

[5] Zarrugh, M.Y. and Radcliffe, C.W. (1978) Predicting metabolic cost of level walking. European Journal of Applied Physiology, 38, 215-223.

[6] Hughes, A.L. and Goldman, R.F. (1970) Energy cost of "hard work". Journal of Applied Physiology, 29, 570572.

[7] Ghori, G.M.U. and Luckwill, R.G. (1985) Responses of the lower limb to load carrying in walking man. European Journal Applied Physiology \& Occupational Physiology, 54, 145-150.

[8] Goh, J.H., Thambyah, A. and Bose, K. (1998) Effects of varying backpack loads on peak forces in the lumbosacral spine during walking. Clinical Biomechanics, 13, 26-31.

[9] Singh, T. and Koh, M. (2009) Effects of backpack load position on spatiotemporal parameters and trunk forward lean. Gait \& Posture, 29, 49-53.

[10] Harman, E., Han, K.H., Frykman, P., Johnson, M., Russell, F. and Rosenstein, M. (1992) The effects on gait timing, kinetics and muscle activity of various loads carried on the back. Medicine \& Science in Sports \& Exer- 
cercise, 24, S129.

[11] Demura, T. and Demura, S. (2010) Relationship among gait parameters while walking with varying loads. Journal of Physiological Anthropology, 29, 29-34.

[12] Information center for building administration, Order for enforcement of the building standards act, 2008.

[13] Murray, M.P., Drought, A.B. and Kory, R.C. (1964) Walking patterns of normal men. Journal of Bone and Joint Surgery, 46, 335-360.

[14] Borghols, E.A.M. (1978) Influence of heavy weight carrying on the cardiorespiratory system during exercise. European Journal of Applied Physiology, 38, 161-169.

[15] Taylor, C.R., Heglund, N.C., McMahon, T.A. and Looney, T.R. (1980) Energetic cost of generating muscular force during running. A comparison of large and small animals. Journal of Experimental Biology, 86, 9-18.

[16] Norman, R.W. (1979) The utility of combining EMG and mechanical work rate data in load carriage studies. Proceedings of the International Society of Electrophysio- logical Kinesiology, 4, 148-149. (Abstract)

[17] Imms, F.J. and Edholm, O. G. (1981) Study of gait and mobility in the elderly. Age and Aging, 10, 147-156.

[18] Menz, H.B., Load, S.R. and Fitzpatrick, R.C. (2003) Age-related differences in walking stability. Age and Ageing, 32, 137-142.

[19] Oberg, T., Karsznia, A. and Oberg, K. (1993) Basic gait parameters: Reference data for normal subjects, 10-79 years of age. Journal of Rehabilitation Research and Development, 30, 210-223.

[20] Lord, S.R., Lloyd, D.G. and Li, S.K. (1996) Sensori-motor function, gait patterns and falls in community-dwelling women. Age and Ageing, 25, 292-299.

[21] Kinoshita, H. (1985) Effect of different loads and carrying systems on selected biomechanical parameters describing walking gait. Ergonomics, 28, 1347-1362.

[22] Martin, J. and Nelson, R.C. (1986) The effect of carried loads on the walking patterns of men and women. Ergonomics, 29, 1191-1202. 